\title{
Identification and bioinformatic characterization of a multidrug resistance associated protein (ABCC) gene in Plasmodium berghei María González-Pons ${ }^{\dagger 1}$, Ada C Szeto ${ }^{\dagger 1,3}$, Ricardo González-Méndez ${ }^{2}$ and Adelfa E Serrano*1
}

Address: ${ }^{1}$ Department of Microbiology, University of Puerto Rico School of Medicine, PO Box 365067, San Juan, PR 00936-5067, USA, ${ }^{2}$ Department of Radiological Sciences, University of Puerto Rico School of Medicine, PO Box 365067, San Juan, PR 00936-5067, USA and ${ }^{3}$ Department of Biochemistry, Universidad Central del Caribe, PO Box 60327, Bayamón, PR 00960-6032, USA

Email: María González-Pons - maria.gonzalez9@upr.edu; Ada C Szeto - ada.szeto@uccaribe.edu; Ricardo GonzálezMéndez - rgonzalez@rcm.upr.edu; Adelfa E Serrano* - aserrano@rcm.upr.edu

* Corresponding author †Equal contributors

Published: 2 January 2009

Malaria Journal 2009, 8: I doi:10.1/86/1475-2875-8-1
Received: 22 August 2008

Accepted: 2 January 2009

This article is available from: http://www.malariajournal.com/content/8/I/I

(C) 2009 González-Pons et al; licensee BioMed Central Ltd.

This is an Open Access article distributed under the terms of the Creative Commons Attribution License (http://creativecommons.org/licenses/by/2.0), which permits unrestricted use, distribution, and reproduction in any medium, provided the original work is properly cited.

\begin{abstract}
Background: The ATP-binding cassette (ABC) superfamily is one of the largest evolutionarily conserved families of proteins. $A B C$ proteins play key roles in cellular detoxification of endobiotics and xenobiotics. Overexpression of certain $A B C$ proteins, among them the multidrug resistance associated protein (MRP), contributes to drug resistance in organisms ranging from human neoplastic cells to parasitic protozoa. In the present study, the Plasmodium berghei mrp gene (pbmrp) was partially characterized and the predicted protein was classified using bioinformatics in order to explore its putative involvement in drug resistance.

Methods: The pbmrp gene from the $P$. berghei drug sensitive, $N$ clone, was sequenced using a PCR strategy. Classification and domain organization of pbMRP were determined with bioinformatics. The Plasmodium spp. MRPs were aligned and analysed to study their conserved motifs and organization. Gene copy number and organization were determined via Southern blot analysis in both $\mathrm{N}$ clone and the chloroquine selected line, RC. Chromosomal Southern blots and RNase protection assays were employed to determine the chromosomal location and expression levels of pbmrp in blood stages.

Results: The pbmrp gene is a single copy, intronless gene with a predicted open reading frame spanning 5820 nucleotides. Bioinformatic analyses show that this protein has distinctive features characteristic of the $A B C C$ sub-family. Multiple sequence alignments reveal a high degree of conservation in the nucleotide binding and transmembrane domains within the MRPs from the Plasmodium spp. analysed. Expression of pbmrp was detected in asexual blood stages. Gene organization, copy number and mRNA expression was similar in both lines studied. A chromosomal translocation was observed in the chloroquine selected RC line, from chromosome 13/14 to chromosome 8, when compared to the drug sensitive $\mathrm{N}$ clone.

Conclusion: In this study, the pbmrp gene was sequenced and classified as a member of the ABCC subfamily. Multiple sequence alignments reveal that this gene is homologous to the Plasmodium y. yoelii and Plasmodium knowlesi mrp, and the Plasmodium vivax and Plasmodium falciparum mrp2 genes. There were no differences in gene organization, copy number, or mRNA expression between $\mathrm{N}$ clone and the RC line, but a chromosomal translocation of pbmrp from chromosome 13/14 to chromosome 8 was detected in RC.
\end{abstract}




\section{Background}

The ATP-binding cassette (ABC) superfamily is one of the largest evolutionarily-conserved families of protein transporters. $\mathrm{ABC}$ proteins play key roles in cellular detoxification of xeno- and endobiotics. Overexpression of certain $\mathrm{ABC}$ proteins, among them the multidrug resistance protein (MDR) and the multidrug resistance associated proteins (MRPs), contribute to drug resistance in a variety organisms ranging from parasitic protozoa to human neoplastic cells.

Membrane transporters, such as the Plasmodium falciparum chloroquine resistant transporter ( $p f c r t$ ) and the Plasmodium falciparum $m d r 1$, which is a member of the $\mathrm{ABC}$ superfamily, have been identified as key contributors in decreasing susceptibility to several anti-malarial drugs [14]. Research to identify additional potential contributors to Plasmodium drug resistance has lead to the identification of new candidate transporter genes, some of which belong to the $\mathrm{ABC}$ transporter superfamily [5-8]. The $\mathrm{ABC}$ transporter superfamily is comprised of eight subfamilies in eukaryotes: $\mathrm{ABCA}, \mathrm{ABCB}, \mathrm{ABCC}, \mathrm{ABCD}, \mathrm{ABCE}, \mathrm{ABCF}$, $A B C G$, and $A B C H$. Proteins within this superfamily were classified based on the sequence and organization of their conserved nucleotide binding domains (NBD). Characteristic motifs within these NBDs are found in the majority of adenine nucleotide hydrolases: the Walker $\mathrm{A}$ and Walker B boxes, ABC signature motif, H (histidine) loop, $\mathrm{D}$ (aspartate) loop, and Q (glutamine) loop [9-13]. In general, functional $\mathrm{ABC}$ proteins contain two NBDs and two transmembrane domains (TMD) consisting of 6-11 transmembrane helices. Genes are organized either as full transporters containing two of each domain or half transporters with one of each (Figure 1c).

Members of the ABCC sub-family have been associated with drug resistance in organisms ranging from bacteria to man. This sub-family is comprised of a variety of proteins some of which have been designated as multidrug resistance associated proteins (MRPs). These proteins serve as primary active transporters of an array of structurally diverse compounds including organic anions such as glucuronide, glutathione (GSH), sulphate, drugs conjugated to GSH, and non-conjugated agents by GSH co-transport $[14,15]$. The human ABCC sub-family consists of 13 members, nine of which are transporters: MRP1, MRP2, MRP3, MRP4, MRP5, MRP6, MRP7, MRP8, and MRP9 $[16,17]$. The human MRP1 has been the most studied among the MRP proteins because of its ability to transport a broad range of anticancer drugs through cellular membranes mediated by GSH co-transport or by the export of GSH-drug conjugates $[14,18]$. In addition, MRPs have been associated with drug resistance in other organisms such as the heavy metal resistance protein MRP-1 in Caenorhabditis elegans [19], the GSH conjugate transport- ers AtMRP1, AtMRP2, and AtMRP3 in Arabidopsis thaliana [20-22], and yeast cadmium factor gene ( $y c f 1)$ in Saccharomyces cerevisiae [23]. Several mrp orthologs have been identified and linked to drug resistance in protozoa such as Trypanosoma brucei and Leishmania spp. In T. brucei, reduced sensitivity to melarsoprol has been linked to the overexpression of the MRP homologue, TbMRPA [24]. In Leishmania, the pentamidine resistance protein 1(PRP1/ ABCC7) and MRPA (formerly known as P-glycoprotein A/ ABCC3) were shown to confer pentamidine resistance and antimony resistance, respectively [25-29].

Homologues of these proteins have been identified in Plasmodium spp., but there is no clear evidence linking this transporter to anti-malarial resistance. Expression of MRP homologues was reported in P. berghei and P. yoelii [7] as well as in $P$. falciparum [30]. The P. falciparum mrp1 gene is an intronless gene with highest mRNA expression in the late trophozoite and schizont stages. The P. falciparum mrp2, however, is mostly expressed in ring stages [31]. Protein expression of these genes has only been reported for pfMRP1, where it has only been detected in the schizont stage, except in the CQ resistant $P$. falciparum strain, FAC8, where it was also detected in the trophozoite stage [30]. Mutations within this gene have been associated with anti-malarial resistance in clinical isolates $[5,6,32]$.

In this study, the pbmrp gene was partially characterized using bioinformatics and molecular biology methods. We sequenced pbmrp and classified it as an ABCC sub-family member. Multiple sequence alignments with MRPs from $P$. y. yoelii, $P$. vivax, $P$. knowlesi and $P$. falciparum reveal a high degree of conservation within transmembrane and nucleotide binding domains. Bioinformatic analyses indicate that pbMRP is homologous to a Plasmodium spp. MRP2 gene. In addition, the gene copy number, structural organization, chromosomal localization and mRNA expression levels of the pbmrp gene were determined in drug sensitive ( $\mathrm{N}$ clone) and the drug resistant derived line RC which was selected under CQ pressure and displays the multidrug resistance phenotype.

\section{Methods \\ Plasmodium berghei lines and maintenance}

Random-bred Swiss albino female mice were infected intravenously with the $P$. berghei drug sensitive $\mathrm{N}$ clone or the RC line which was selected under CQ pressure and displays the multidrug resistant phenotype. These lines were kindly provided by Wallace Peters [33,34]. Mice infected with the RC line were dosed once with CQ $1 \mathrm{hr}$ after infection in order to maintain drug selection pressure [35]. Platelets and white blood cells were removed from the infected blood by glass bead and CF-11 cellulose columns, respectively. Infected red blood cells (IRBCs) were 
a

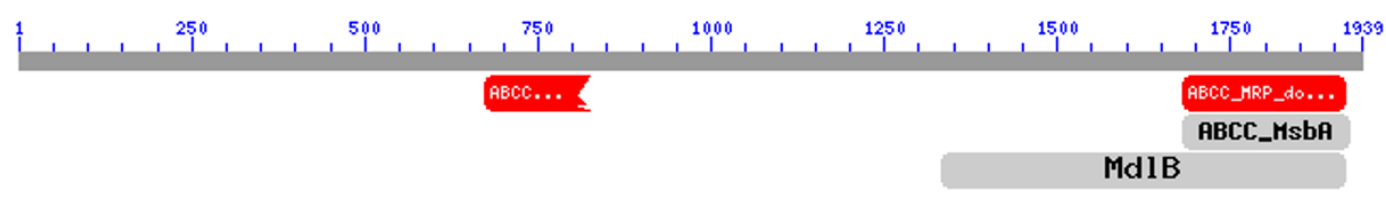

b

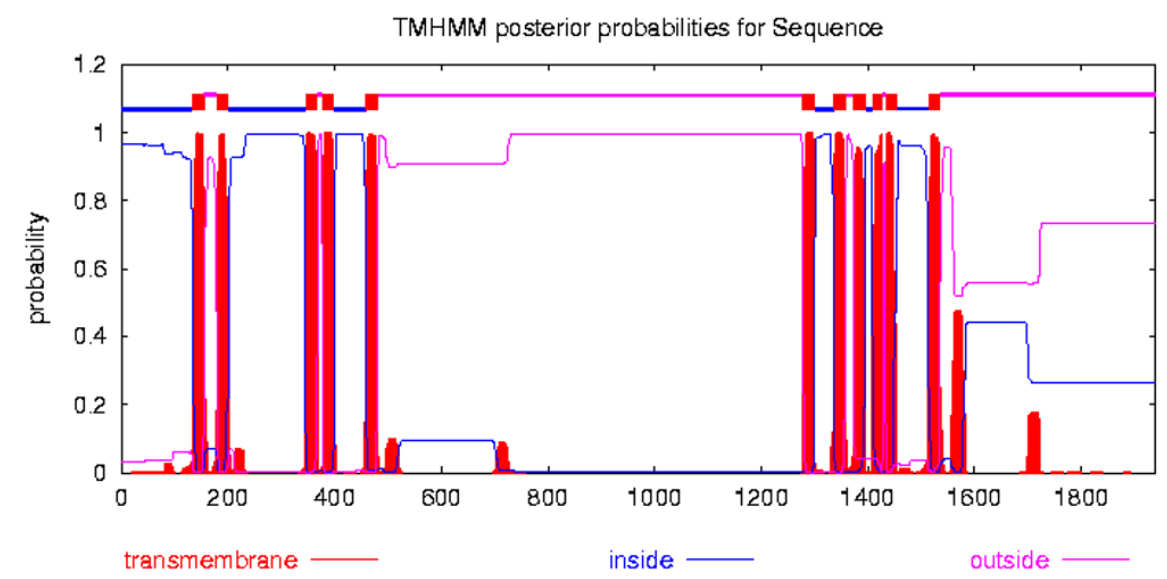

C

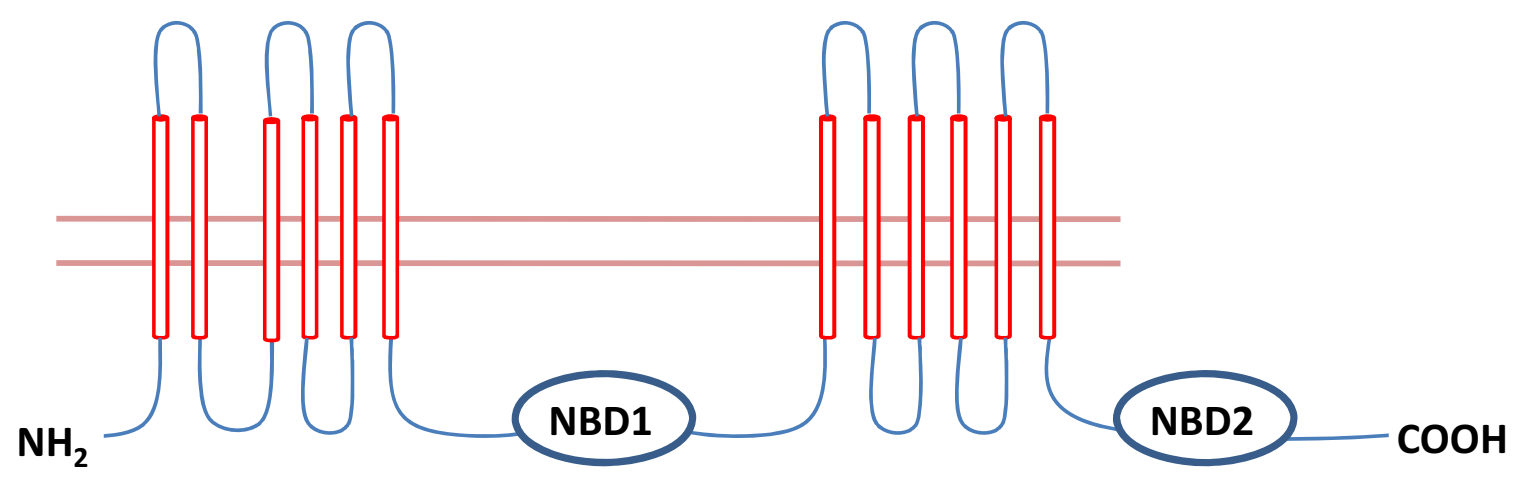

Figure I

Classification and structural organization of pbMRP. (A) Conserved domain database summary view of the domain model identifying $A B C C$ specific NBDs within pbMRP. These domains are depicted by red boxes under the corresponding regions within the predicted protein sequence. (B) Graphical representation the pbMRP predicted topology generated by the TMHMM server. Results were also confirmed using the DAS server transmembrane prediction. Predicted transmembrane helices are depicted in red. (C) Diagram of pbMRP embedded in the membrane. The protein contains two TMDs and two ATPbinding NBDs represented by red cylinders and blue circles, respectively.

differentially lysed with $0.15 \%$ saponin [36] and free parasites were collected.

\section{Nucleic acid extraction}

Plasmodium berghei DNA was isolated by phenol/chloroform extraction [37]. Total parasite RNA was extracted using RNA STAT-60 (Tel-Test Inc.) according to manufacturer's specifications. Chromosome blocks were prepared as described by Serrano et al [38].

\section{PCR amplification, cloning and sequencing of the $P$. berghei mrp}

Plasmodium berghei genomic DNA from the $\mathrm{N}$ clone was subjected to PCR amplification using primers designed based on the $m r p$ gene identified in P. y. yoelii [7] (Additional file 1). Amplification of pbmrp fragments was carried out under standard conditions. Amplified products were cloned into pGEM $^{\circledast}$-T-EASY (Promega) plasmids according to the manufacturer's instructions. Purified 
clones were sequenced using the Applied Biosystems Big Dye Terminator V3.0 sequencing chemistry (Davis Sequencing Inc., CA). Every position of the putative open reading frame for the pbmrp gene was sequenced at least twice in each direction.

\section{Bioinformatic analyses}

The pbmrp gene was assembled by aligning the overlapping translated sequence of the P. berghei cloned PCR products along the translated $P$. y. yoelii mrp gene [GenBank: XP 725434]. Once the entire putative open reading frame (ORF) was assembled, the predicted amino acid sequence was analysed to identify conserved motifs using the InterProScan sequence search tool [39] and the Conserved Domain Search service [40]. The presence of internal transmembrane domains and their organization was predicted using the TMHMM v. 2.0 prediction server [41] and the DAS transmembrane prediction server [42]. Plasmodium mrp sequences were retrieved by sequence similarity searches using the pbmrp translated sequence from the PlasmoDB ver. 5.4 [43] and the BLAST search tool hosted at PlasmoDB and at NCBI $[44,45]$. To obtain the closest human homologue, we performed sequence similarity searches against human genome protein database using the $P$. berghei $m r p$ predicted protein sequence.

The following sequences were recovered and used for subsequent sequence analyses: P. falciparum mrp1 [GenBank: ABV24500], P. falciparum mrp2 [GenBank: ABV24501], $P$. vivax mrp1 [GenBank: XP 001612680], P. vivax mrp2 [GenBank: XP 001617379], P. knowlesi mrp [GenBank: CAQ42240], P. berghei mrp [GenBank; AAS46595], and $P$. $\gamma$. yoelii $m r p$ [GenBank: XP 725434]. Multiple sequence alignments and analyses were carried out using the ClustalW program hosted at the European Bioinformatics Institute [46]. Alignments were visualized by using GeneDoc (provided by the Pittsburg Supercomputing Center) [47]. The phylogenetic analysis of the MRPs from Plasmodium was performed as follows. The predicted protein sequences for the MRP genes from Plasmodium listed in Table 1 and the MRP2 from Homo sapiens [GenBank: CAB45309] (which was used as outgroup for placement of the root) were retrieved from NCBI in FASTA format. The multiple sequence alignment was done with ClustalW as described above. The alignment was submitted to the GBlocks server to trim the sections of large variability that would affect the phylogenetic analysis [48]. The GBlocks analysis was carried out using the less restrictive settings of smaller blocks and permitting gaps within the blocks. The suggested multiple sequence alignment, which retained approximately $49 \%$ of the alignment positions, was taken. The phylogenetic analysis was done using the PHYLIP suite of programs [49]. The program SEQBOOT was used to generate a bootstrapped data set of 500 replicates. The program PROTDIST was used to generate the distance matrices for the analysis. The rooted phylogenetic trees were constructed according to the program NEIGHBOR using the neighbor-joining algorithm [50]. The program CONSENSE was used to build a rooted consensus tree using an extended majority rule.

\section{Southern blot analysis}

Southern blots and subsequent hybridizations were performed as described by Gervais et al., 1999 [51]. Genomic DNA (gDNA) from the P. berghei lines, $\mathrm{N}$ clone and RC, were digested with HindIII, EcoRI, or EcoRV. Membranes were hybridized with $5^{\prime}$ and $3^{\prime}$ pbmrp specific probes which were amplified with the following primer combinations: pbmrp 5' (Forward primer-TAATATAGATAAAAATGAGGGGG and Reverse primerAAAGTGCATAACAGTTACTTCC) and pbmrp 3' (Forward primer-TACAATAGTTATGGCAATATTAG and Reverse primer-CATCAATAATTTCTTATCAGA). Hybridizations were carried out at $65^{\circ} \mathrm{C}$ in $2 \times$ sodium chloride/sodium citrate solution (SSC) with $0.1 \%$ sodium dodecyl sulphate (SDS).

\section{Chromosomal blot and localization}

Plasmodium berghei (N clone and RC) chromosomes were separated by pulse-field gel electrophoresis [52,38]. To optimize separation (BioRad CHEF DRII) running conditions were modified as follows: $125 \mathrm{~V}, 120$-s pulses for 24 $\mathrm{h}$ and 300 -s pulses for $24 \mathrm{~h}$ at $14^{\circ} \mathrm{C}$. Chromosomes were blotted onto a Zeta Probe membrane (BioRad) and

Table I: Plasmodium MRP predicted protein sequence similarity to pbmrp from the Plasmodium berghei N Clone line

\begin{tabular}{|c|c|c|c|c|c|c|}
\hline Gene* & $\begin{array}{c}\text { GenBank } \\
\text { accession number }\end{array}$ & $\begin{array}{l}\text { Nucleotide } \\
\text { length (nt) }\end{array}$ & $\begin{array}{l}\text { Predicted protein } \\
\text { length (aa) }\end{array}$ & $\begin{array}{l}\text { Percent sequence } \\
\text { identity to pbmrp }\end{array}$ & $\begin{array}{l}\text { Percent amino acid } \\
\text { similarity to pbmrp }\end{array}$ & E value \\
\hline PyMRP & XP 725434 & 5928 & 1976 & $82 \%$ & $88 \%$ & 0 \\
\hline pkMRP & $\overline{C A Q 42240}$ & 6051 & 2016 & $36 \%$ & $54 \%$ & 0 \\
\hline pvMRP2 & XP 001617379 & 6072 & 2024 & $36 \%$ & $53 \%$ & 0 \\
\hline pfMRP2 & $\underline{A B V 24501}$ & 6327 & 2108 & $36 \%$ & $56 \%$ & 0 \\
\hline PvMRPI & $\mathrm{XP001612680}$ & 5181 & 1727 & $32 \%$ & $51 \%$ & $2.3 \mathrm{e}^{-273}$ \\
\hline pfMRPI & $\underline{A B V 24500}$ & 5469 & 1822 & $32 \%$ & $53 \%$ & $5.9 e^{-252}$ \\
\hline
\end{tabular}

* P. y. yoelii MRP (PyMRP), P. knowlesi MRP (pkMRP) P. vivax MRP2 (pvMRP2), P. falciparum MRP2 (pfMRP2), P. vivax MRPI (pvMRPI), P. falciparum MRPI (PFMRPI) 
hybridized at $65^{\circ} \mathrm{C}$ in $2 \times \mathrm{SSC} / 0.1 \%$ SDS with a radiolabeled $P$. berghei $m r p$ specific $3^{\prime}$ probe. Subsequently, the membranes were stripped and hybridized to known $P$. berghei chromosome markers: a chromosome 13/14 probe (probe 9.45 kindly provided by Dr. Marta Ponzi) [52] or a chromosome 8 probe directed to a known gene previously localized to this chromosome, the P. berghei $\gamma$ glutamylcysteine synthetase gene (pbggcs) [53,54].

\section{RNase protection assay (RPA)}

Alpha-32P UTP labelled riboprobes for $p b m r p$ and $\beta$-tubulin ( $\beta t u b$, used as a normalizing control) were synthesized in vitro by antisense transcription using the T7 RNA polymerase (Maxiscript ${ }^{\circledR}$ SP6/T7 Kit, Ambion). Riboprobes were co-precipitated with dilutions of total RNA from the $P$. berghei sensitive $\mathrm{N}$-clone or the drug resistant derived line RC. RPA was performed using the RPAIII ${ }^{\mathrm{TM}}$ system (Ambion, Austin, Texas) according to the manufacturer's instructions. Protected RNA hybrids were resolved on denaturing acrylamide gels which were subsequently exposed to autoradiography films. Autoradiograms were scanned and analysed using Quantity One 1D Analysis Software (Bio-Rad, v. 4.4). Ratios of the densities of the normalized pbmrp signals were subsequently normalized to the drug sensitive $\mathrm{N}$-clone to estimate mRNA expression levels in RC.

\section{Results}

Identification and characterization of an mrp homologue in $\mathbf{P}$. berghei

An $m r p$ homologue was identified in $P$. berghei using primers designed to PCR-amplify the pbmrp gene in the drug sensitive $\mathrm{N}$ clone. Sequence analysis of the pbmrp gene shows an open reading frame (ORF) of 5820 nucleotides. This single exon gene encodes a predicted protein of 1939 amino acids (Additional file 2). Based on the NBD amino acid sequence, the NCBI's Conserved Domain Database classified pbMRP as a member of the
ABCC transporter sub-family (Figure 1a). This transporter possesses the general structural features associated with MRPs. Transmembrane helix predictions by both the DAS and TMHMM transmembrane prediction servers predict that pbMRP has 12 transmembrane helices organized into two TMDs and that both, the N-terminal and C-terminal, are intracellular. A model presenting domain organization of the predicted pbMRP amino acid sequence, which contains two TMDs and two NBDs, is shown in Figure 1c. Five of the six characteristic motifs associated with $A B C$ NBDs were found within the NBDs of pbMRP (Figure 2). In NBD1, the Walker A, Q loop, ABC motif, Walker B and the $\mathrm{D}$ loop were identified, with a large variable insertion between the $\mathrm{ABC}$ motif and the Walker $\mathrm{B}$ motif. Within NBD2, the Walker A, Q loop, ABC motif, Walker B and the $\mathrm{H}$ loop were found. However, the H loop in NBD1 and the D loop within NBD2 were not found (Figure 2). Consensus motif sequences and the Plasmodium spp. motif sequences found within the NBDs are reported in Table 2.

The predicted pbMRP amino acid sequence was used to identify homologues in other Plasmodium species by sequence similarity searches in PlasmoDB. A partial sequence was found in the $\mathrm{P}$. berghei genome, two homologous genes in P. falciparum (pfmrp1 and pfmrp2), two in P. vivax (pvmrp1 and pvmrp2), one in $P$. knowlesi (pkmrp), and one in P. y. yoelii (pymrp). A multiple sequence alignment of the protein sequences shows that pbMRP has highest similarity with its homologue in the rodent malaria species, P. y. yoelii (Figure 3 and Additional file 3). Sequence identity between pbMRP and the MRPs from Plasmodium spp. ranges from $82-32 \%$ with the highest percent identity with pyMRP and the lowest with pfMRP1 (Table 1). BLAST results show that pbMRP is more closely related to pyMRP, pkMRP, pfMRP2 and pvMRP2 with expectation values reported as 0 although it also exhibits a high degree of relatedness to pfMRP1 and pvMRP1 (Table 1). Sequence similarity searches against

Table 2: Motifs within Plasmodium spp. MRP nucleotide binding domains

\begin{tabular}{|c|c|c|c|c|}
\hline Nucleotide Binding Domain & Motif & Consensus Sequence & Consensus in Plasmodium spp. & Location in pbMRP \\
\hline \multirow[t]{6}{*}{ NBDI } & Walker A & GxxxxGK $[S, T]$ & $\mathrm{G}[\mathrm{D}, \mathrm{N}][\mathrm{I}, \mathrm{V}] \mathrm{GSG}[\mathrm{E}, \mathrm{K}] \mathrm{T}$ & $714-722$ \\
\hline & Q loop & $X Q x$ & $\mathrm{PQ}[\mathrm{I}, \mathrm{F}]$ & $753-755$ \\
\hline & $A B C$ motif & LSGGQ & LSKGQ & $808-812$ \\
\hline & Walker B & XILxDE & LYL [L, F]DD & $954-959$ \\
\hline & D loop & LD & LD & $964-965$ \\
\hline & H loop & $\mathrm{XHx}$ & Not identified & \\
\hline \multirow[t]{6}{*}{ NBD2 } & Walker A & GxxxxGK $[S, T]$ & $\mathrm{G}[\mathrm{K}, \mathrm{R}] \mathrm{SGAGKS}$ & $1705-1712$ \\
\hline & Q loop & XQx & $\mathrm{PQS}$ & $1752-1754$ \\
\hline & $A B C$ motif & LSGGQ & $L[S, A] L V R$ & $1835-1839$ \\
\hline & Walker B & XILxDE & $\mathrm{L}[\mathrm{L}, \mathrm{V}, \mathrm{I}] \mathrm{LIDE}$ & $1849-1854$ \\
\hline & D loop & LD & Not identified & \\
\hline & H loop & $\mathrm{XHx}$ & {$[\mathrm{S}, \mathrm{A}] \mathrm{HD}$} & $1895-1897$ \\
\hline
\end{tabular}




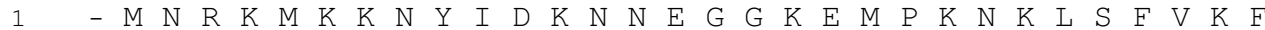

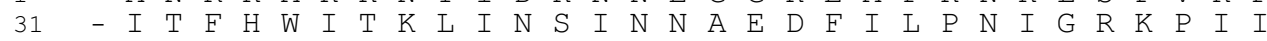

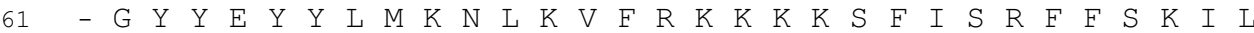

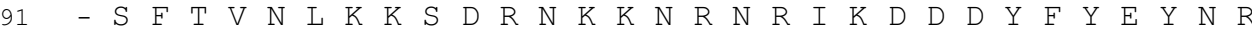

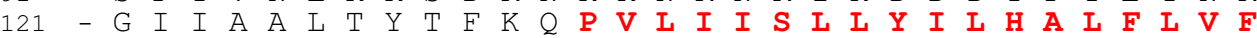
151 - V A I C I E K Y I S I I K G H H V F S P I I O S K T A K I I 181 - S A F V L I M V L S I N L F M D S A V S Y I H N K I I I I D 211 - E V T V M H F L Y K I N M G V F N H C I L 241 - N L H E I S N N N S E N S T C A N I D S Y K N N T H G T S K 271 - N Y I I K V E N E D E N A E Y K N E T N Q S N A N T T I S T 301 - $N$ N I T D F S K K N D I N N K I E D N E N V I E H N 331 - G I N I Y N I M F I D T P S L I Y F I S S A I I A N G M I I 361 - K L V I S F Y M F Y H K M G K D S I I I G I F L V I L L I Y 391 - I I L L C E L I S S M L K K K Y L K Y O D K R I D N

421 - L K E Y K I M K M F N W E S I A F D Y V 451 - C K Y R I Y L S S I S N Y I N A I S V H C V E I V I F F V Y

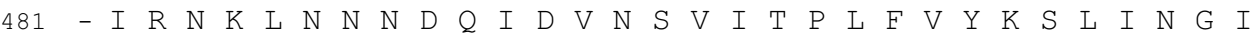
$\begin{array}{lllllllllllllllllllllllllllllll}511-V & - & S & F & P & T & I & F & N & N & L & L & E & G & P & I & S & N & D & R & V & N & K & Y & I & N & H & Y & F & H & D\end{array}$

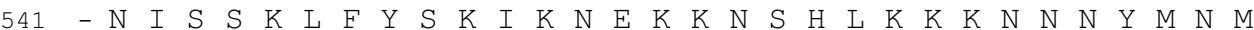

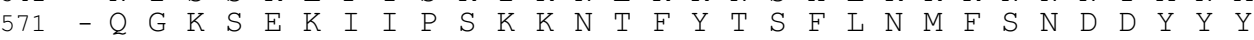

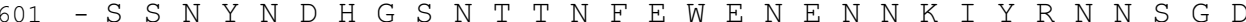

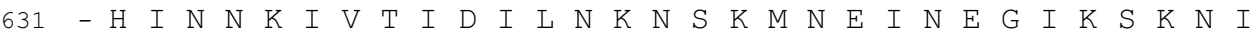
661 - L D E K Y G I D K K T I I K L E 691 - Q S K N M K L K N V N F T L K N N T I A I I I G D I G S G

721 - T L F F N S I I G K F K I I N 751 - Y A P Q I N W L S D G T I R 781 - A I S Q 811 - G Q K S R I S L A R S L Y Y H Y I N

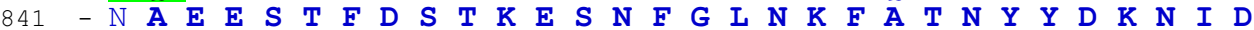
$871-$ N M K S V R I S K S I K N F T L H N D N $901-$ Y N D E S E Q I K G N N K N S K S D T N S F I S D C K F 931 - P D L Q 961 - F T S I L D P 991 - G I V I T I N E N A F N S F I M K D I I E

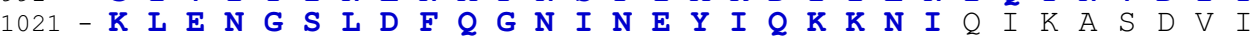

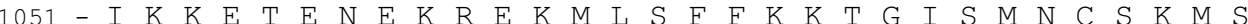
1081 - D Q V F Y M S M S L E L C Y Q $N$ N 1111 - E S S S L S T S V 1041 - K E L K L L H H I K A E A N N E T P

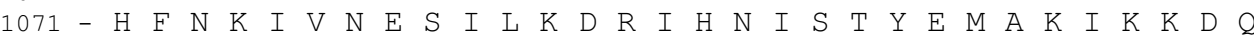
1201 - I R K Y I G N F I V D T K G N N E M K C L K N K K T T H I N 1231 - F E E E I N A $M$

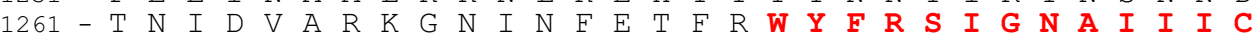
1291 - I I I F I I F S I F I D E V K N M L L F I V 1321 - K S Y Y E E I I Q T K I V V Y L K 1351 - S Y M V I A H G I M I S A K A I H T E V F K S M I Y A P I P 1381 - A F Y S H N I G N I I N R F I I D I H T L D N G I I K R C 1411 - K S F F T V S K F I S T V I L L I F M F K K T Y I M L 1441 - I I I V Y Y G I F K K Y S I A C K E A O R G Y L C S H 1471 - C S I F S N T I H G K D I I N I Y K K 1501 - I Y A L R N F T L F K W G I T A W A S I Y I Q L V S L C I T 1531 - S F Y I L Y 1561 - S E V V I G 1591 - E M C S I Q S L Q E L S K I K N I S D E T

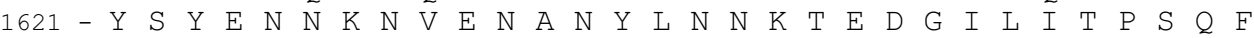
1651 - P K S K Y G I E F K N V Y V S Y K K K V Y I I D K I I K N 1681 - Y A N E K S C L R N I N F Y A I K S Q N I G I I G K S G A G

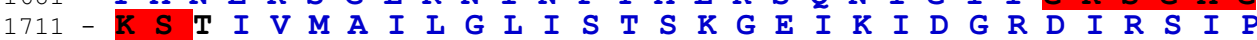
1741 - L N E K K K I I G I L P O S S F V F S H W N I R T Y I D $1771-Q \mathbf{K}$ F S D N E I I D A F E T I G I N L T C A D I N K K Y I Y K

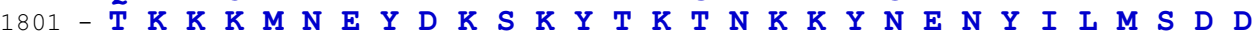
1831 - S I R Y L S L V R I Y L N R N N Y K L I L I I D E I P P V V

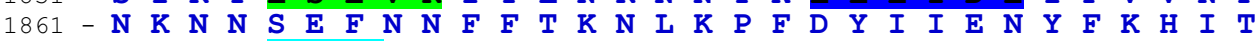
1891 - I I I I $\mathbf{S}$ H 1921 - Y S D V E T Q T Q L A N I I Q D Q A N

Figure 2

Domain and motif organization in the pbMRP predicted protein sequence. The pbMRP is comprised of 2 TMDs (red) and two NBDs (blue). Conserved sequence motifs within the NBDs are highlighted: the Walker A motif (red), the Q loop (yellow), the ABC motif (green), the Walker B motif (blue), the D loop (pink) and the H loop (turquoise). 
A
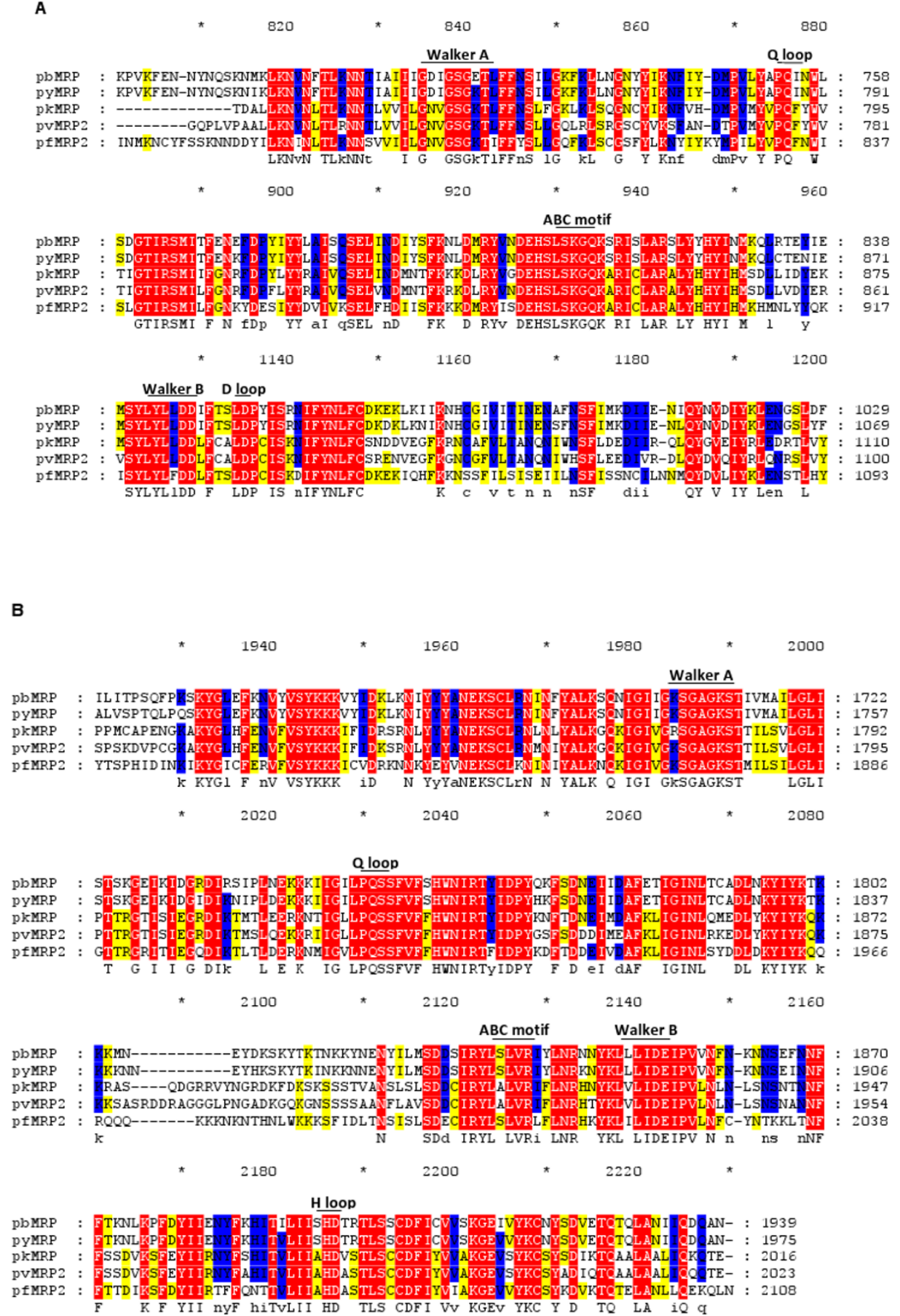

Figure 3

Alignment of the of Plasmodium spp. MRP NBDs. Alignment of predicted NBDI (A) and NBD2 (B) amino acid sequences from Plasmodium spp. mrp genes were performed using the ClustalW algorithm with the Blosum matrix (all other parameters set as default). Amino acids with a $100 \%$ identity are shaded in red, $99-75 \%$ identity are in blue and $74-50 \%$ identity in yellow. Conserved Walker A, Q loop, the ABC motif, Walker B motifs as well D loop and $\mathrm{H}$ loop motifs are indicated above the corresponding sequence. Within the NBDI there is a large non conserved region in NBDI between the ABC motif and the Walker $B$ and $D$ loop containing region (from position 961 to $1 \mathrm{I} I 0$ in the multiple sequence alignment) which is not shown in this figure. For the complete multiple sequence alignment refer to Additional file 3. 
the human genome protein database show that MRP2 is the closest homologue to pbMRP with an expectation value of 9e-30. The phylogenetic gene tree supports the results presented in Table 1 (Figure 4). The MRP1 subfamily and the MRP2 subfamily are clearly grouped into separate clusters indicating these are paralogous genes. The bootstrap values for all branches are above 97 percent indicating highly significant support for the clades seen in the gene tree.

\section{pbmrp gene organization in drug sensitive and resistant lines}

To explore whether pbmrp genetic rearrangements and/or an increase in gene copy number contribute to drug resistance in resistant $P$. berghei lines, Southern blot analysis were performed on restricted gDNA from each of the $P$. berghei lines (Figure 5). The 3' probe hybridized to a single band for each enzyme used. Similarly, the hybridization with the 5 ' probe also resulted in a single band for each enzyme. Results show no difference in the band patterns and hence there is no difference in the genetic organization of pbmrp between the drug sensitive $\mathrm{N}$ clone and the $\mathrm{CQ}$ resistant $\mathrm{RC}$ line. In addition, there is no difference in hybridization intensities between the drug sensitive $(\mathrm{N}$ clone) and resistant line (RC) indicating the same pbmrp gene copy number in both parasite lines.

\section{Chromosomal location of pbmrp in drug sensitive and resistant lines}

In this study, pbmrp was mapped in drug sensitive and drug resistant line. In the drug sensitive, $\mathrm{N}$ clone, the

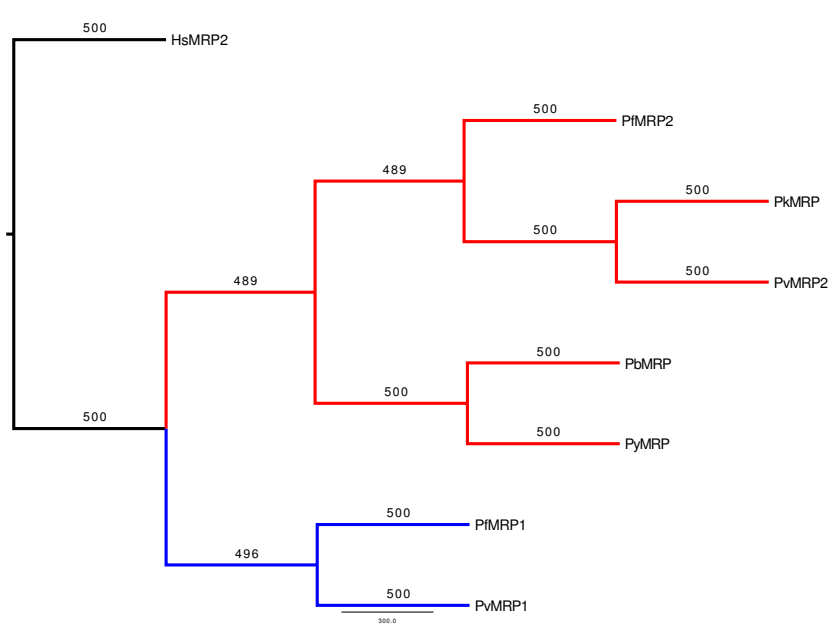

Figure 4

Consensus rooted gene tree for Plasmodium multidrug-resistance associated proteins. Consensus rooted gene tree was generated with the PHYLIP suite of programs using the neighbor-joining algorithm. The branch labels represent the bootstrap counts. The Homo sapiens MRP2 was used as an outgroup for root placement. MRPs have been designated as described in Table I.

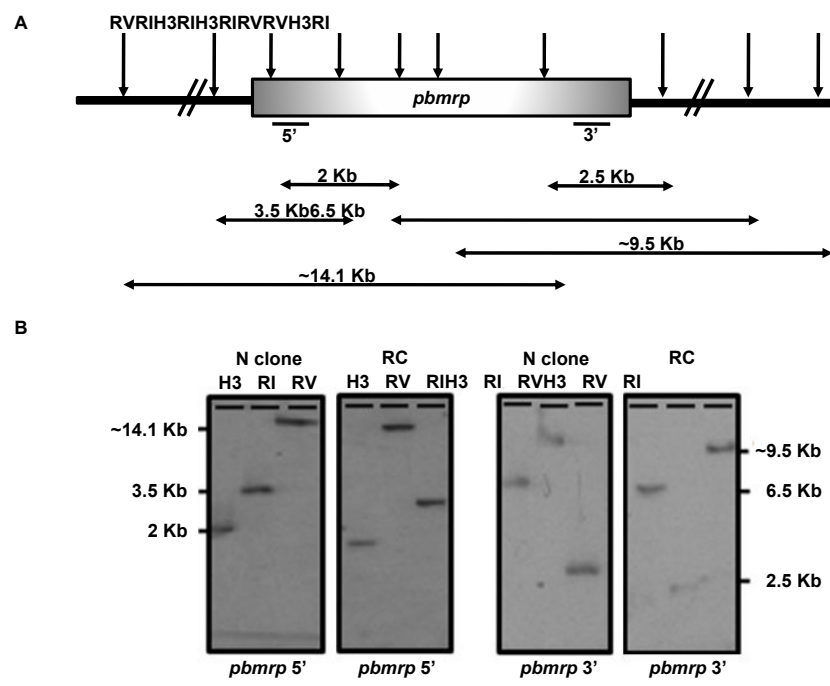

Figure 5

Southern Blot Analysis of the pbmrp Gene. (A) Diagrammatic representation of the pbmrp locus organization. Black arrows above the locus represent the restriction sites within the gene or in flanking areas. Below the coding region, the black lines represent the $5^{\prime}$ and $3^{\prime}$ specific probes used. Genomic DNA from $N$ clone and RC line was digested with Hind III (H3), Eco RI (RI), and Eco RV (RV). The predicted bands and their sizes are depicted by black arrows. (B) Both probes hybridize to a single band for each of the enzyme used: 14.I kb for RV, $3.5 \mathrm{~kb}$ for RI, and $2.0 \mathrm{~kb}$ for H3 (left panel) and $9.5 \mathrm{~kb}$ with $\mathrm{Rl}, 6.5 \mathrm{~kb}$ with $\mathrm{H} 3$, and approximately $2.5 \mathrm{~kb}$ with RV (right panel), respectively.

pbmrp gene was localized to the largest chromosome band corresponding to chromosome 13/14, which co-migrate in $P$. berghei (Figure 6). However, in CQ selected line (RC), the pbmrp gene was detected only in chromosome 8 indicating that a translocation event took place. This translocation was observed using pbmrp specific probes targetting the 3 ' terminus.

\section{Comparison of pbmrp expression profiles in drug sensitive and resistant lines}

RNase protection assays were employed to measure pbmrp expression at the level of transcription in the drug sensitive $\mathrm{N}$ clone and the drug resistant line, RC. Expression in $\mathrm{RC}$ was $1.26 \pm 0.49$ (mean \pm std.dev) relative to $\mathrm{N}$ clone pbmrp RNA expression levels (Figure 7). Similar pbmrp transcription levels were detected in RC when compared to $\mathrm{N}$ clone.

\section{Discussion}

Energy-dependent transporters are responsible for maintaining the metabolic homeostasis in organisms. Understanding transporters involved in cellular detoxification and/or drug efflux in Plasmodium spp. can provide critical 


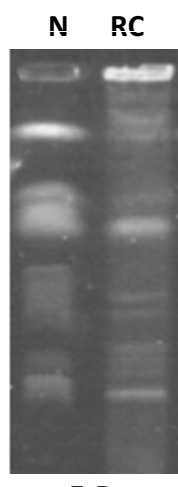

$\mathrm{EtBr}$

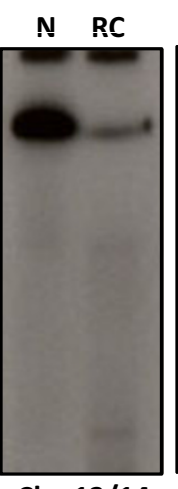

Chr. 13/14

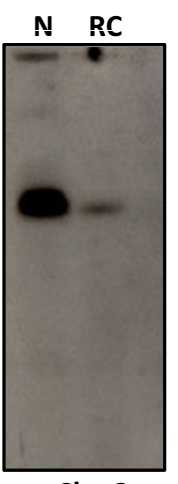

Chr. 8

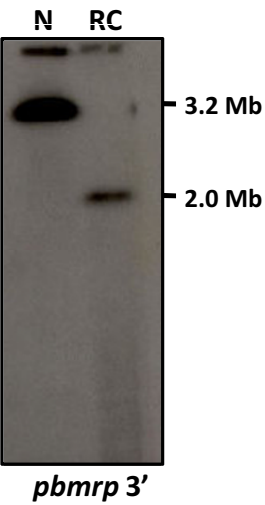

Figure 6

Chromosomal location of the pbmrp gene. Representative results for the chromosomal location of pbmrp gene in the $P$. berghei $\mathrm{N}$ clone and $\mathrm{RC}$ line. $P$. berghei chromosomes were visualized with ethidium bromide $(\mathrm{EtBr})$ prior to transfer. Chromosome membranes were hybridized with a 3' specific pbmrp probe, a chromosome I3/I4 specific marker [52] or to a chromosome 8 probe [54]. Note, that the pbmrp gene was localized to chromosome I3/I4 in N clone and to chromosome 8 in the CQ selected line (RC).

information about their function and their potential as new drug targets. Plasmodium berghei, a rodent malaria model, is a proven and valuable tool for studying Plasmodium biology as well as the development of resistance to anti-malarials which continues to be global health problem. In this study, a multidrug resistance associated protein gene in $P$. berghei was sequenced. This gene, pbmrp, was classified and characterized using bioinformatics. The pbmrp gene organization, copy number, and gene expression levels were compared between the drug sensitive $\mathrm{N}$ clone and the CQ selected (RC) P. berghei line.

The pbmrp gene has an intronless ORF of 5820 nucleotides and is predicted to encode a protein comprised of 1939 amino acids. NCBI's Conserved Domain Database classified pbMRP as a member of the ABCC transporter subfamily (Figure 1a). Using the predicted pbMRP sequence, six homologues were identified in four Plasmodium species (P. falciparum, P. vivax, P. knowlesi and P. y. yoelii) by sequence similarity searches in the PlasmoDB and in NCBI. We note that at the time the analyses were performed the annotation of the proteins at NCBI and PlasmoDB is only complete for the pfMRP2 and pfMRP1. For pvMRP1 and pvMRP2 the annotations are ABC transporter and multidrug-resistance associated protein, respectively. The classification as MRP1 and MRP2 is based on the results presented here from similarity searches and phylogenetic analyses. For pkMRP2, pyMRP2 and pbMRP2 the annotations are transporter/ putative mrp, $\mathrm{ABC}$ transporter, and multidrug-resistance
A

Probe
Line
$\mu \mathrm{g}$

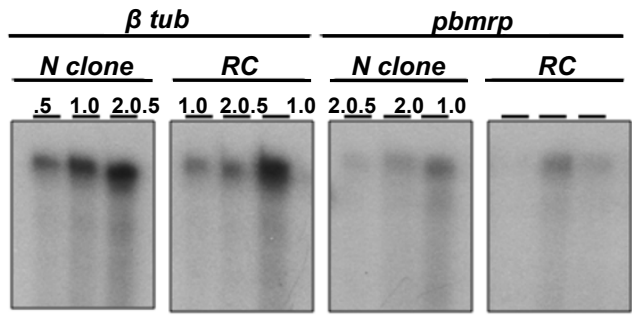

B

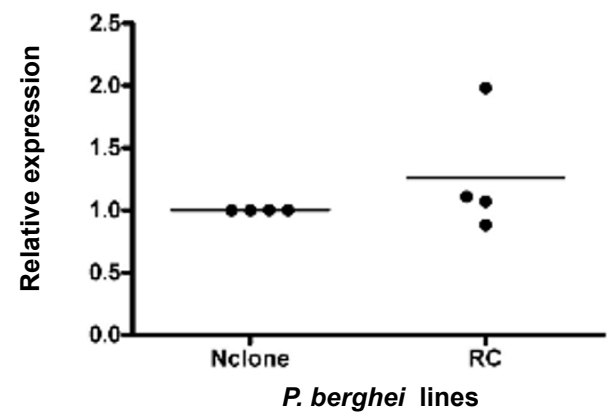

Figure 7

Determination of pbmrp transcript levels in sensitive and drug resistant $P$. berghei parasites. (A) Representative results of an RPA analysis using total RNA dilutions from the drug sensitive $\mathrm{N}$ clone or the $\mathrm{CQ}$ selected $\mathrm{RC}$ line showing protected fragments with the $\beta$ tub or pbmrp riboprobes. $\beta$ tub was included as a normalizing control. (B) Densitometric analysis of pbmrp expression. Densities of the normalized pbmrp signals were subsequently normalized to the drug sensitive $\mathrm{N}$-clone to estimate the relative mRNA expression levels in RC. The horizontal line represents mean relative expression of four experiments.

associated protein respectively. As before, classification as MRP2 is based on the results presented here from similarity searches and phylogenetic analyses. At this time, the presence of two mrp genes appears to be unique for the two human malaria species, $P$. falciparum and $P$. vivax (Table 2). An additional mrp gene may confer a biological advantage for $P$. falciparum or $P$. vivax with respect to fitness or the evolution of drug resistance but this has yet to be proven experimentally. BLAST results support that from an evolutionary standpoint pbMRP is more closely related to PyMRP, pkMRP, pfMRP2 and pvMRP2 rather than to pfMRP1 and pvMRP1 (Table 1). Interestingly, sequence similarity searches against the human genome show that pbMRP is more closely related to the MRP2. Taken together, the fact that pbMRP is more similar to pvMRP2 and pfMRP2 in addition to having the closest relatedness to the human MRP2 confirms that the $P$. berghei transporter is a member of the ABCC MRP2 subfamily. The phylogenetic analysis presented in Table 1 and Figure 4 supports the hypothesis that the MRP2 fam- 
ily is the ancestral family of MRPs in Plasmodium. It is noteworthy that at this time the MRP1 sub-family only appears in parasites that infect humans. Given the lack of knowledge about the function of the MRPs in Plasmodium, it is not possible to assess the significance of the finding at this time. It is also important to note that the MRP2 clade groups the gene from $P$. knowlesi with that of $P$. vivax, in agreement with published phylogenies [[55] and references therein]. Human MRP2 is involved in the terminal phase of detoxification and excretion of endogenous and xenobiotic organic anions in a unidirectional manner. This protein actively transports glutathione, glucuronate, or sulphate conjugates in addition to a variety of non-conjugated anionic substances including glutathione and glutathione disulfide [56]. Although MRP2 has broad substrate specificity, it has highest affinity for gluconarate and GSH conjugates of lipophilic substances $[57,58]$. Based on the sequence similarity to MRP2 and taking into account the biological function of this membrane transporter, it would be reasonable to suggest that the biological function of pbMRP might be related to cell detoxification and the secretion of conjugated and/or non conjugated endogenous and xenobiotic anions. In addition, human MRP2 has been shown to confer drug resistance to multiple chemotherapeutic agents in cell lines expressing the recombinant protein or antisense constructs [59-61]. Given that MRP2 confers resistance in human cells in addition to the fact that the overexpression of homologues in Leishmania and T. brucei $[24,26,29]$ is associated with drug resistance raises the possibility that pbmrp may also contribute to this phenomenon.

The pbMRP displays the typical core ABCC/MRP domain organization of two units of a TMD and a NBD (Figure 1c). All human MRPs, the best and most completely characterized members of this sub-family, possess this typical core structure with the exception of MRP1, MRP2, MRP3, MRP6 and MRP7 which have an additional N-terminal region composed of a third transmembrane domain (TMD0) $[62,63,17,64]$. The pbMRP does not possess this additional TMD0 (Figure 1b) similar to the other members of human MRP family such as MRP4, MRP5, MRP8 and MRP9 [63,65-67].

The NBD size and organization in the MRPs of the Plasmodium spp. studied were similar to those described in other organisms. A high level of similarity was observed in multiple sequence alignments, in particular within the NBDs with the exception of a large, non conserved insertion of approximately 103 amino acids in NBD1 (from position 961 to 1110 in the multiple sequence alignment) (Figure 3, Additional file 3). Characteristic NBD motifs such as the Walker A, Q loop, ABC motif, Walker B, D loop and the $\mathrm{H}$ loop were found within the NBDs (Figure 3). All of the characteristic motifs were identified with the excep- tion of the $\mathrm{H}$ loop in NBD1. This NBD is unique in the sense that there is an insertion between the $\mathrm{ABC}$ motif and the Walker $\mathrm{B}$ motif. This insertion was present in all the Plasmodium MRP sequences studied. The Walker B motif and the D loop were identified after this large insertion in the multiple sequence alignment. The location and sequence of the Walker $\mathrm{B}$ motif in the region following the insertion is similar to that described as the Walker B in pfMRP1 [30]. The D loop could not be identified in the MRP NBD2 in all the Plasmodium species studied (Figures 2 and 3). The failure to identify the H loop in NBD1 and the D loop in NBD2 may be due to a lack of conservation in the sequences encompassing these motifs in Plasmodium. Both the $\mathrm{H}$ loop and the $\mathrm{D}$ loop have structural functions within the NBD although their precise role in the molecular mechanism is not clear. The H-loop histidine contacts the bound nucleotide and the D loop may form a hydrogen bond with the Walker A backbone $[13,68]$. Remarkably, the sequences characteristic of an $\mathrm{ABC}$ transporter NBD were highly conserved among the Plasmodium species studied but these are not strictly conserved when compared to the consensus sequences described for these motifs in vertebrates (Table 2).

The structure and function of MRP2 genes in Plasmodium has not been described. In neoplastic cells as well as in Leishmania, gene duplication and/or overexpression correlate with the drug resistant phenotype $[69,70]$. In this study, the pbmrp gene was shown to have has similar gene organization and the same gene copy number in both the drug sensitive $\mathrm{N}$ clone and the CQ selected RC line (Figure 5). In addition, this gene was not differentially expressed at an mRNA level between these two lines (Figure 7). However, amplification or increased expression might have been lost upon removal of drug pressure given that RC line was not under continuous CQ pressure in these experiments. In primary cultures of rat brain endothelial cells treated with dexamethasone, increased expression of mrp2 at the mRNA and protein level was detected in a concentration dependent manner. This increase in expression was reversible in the absence of drug pressure [71]. In a CQ selected $P$. falciparum clone, an increase in the size of chromosome 3 was observed with increased CQ pressure as a result of DNA amplification whereas removal of CQ selection resulted in the return of chromosome 3 to its original size [72]. Single nucleotide polymorphisms within $p f m r p 1$ have been associated with anti-malarial resistance in field isolates $[5,6,32]$. Nevertheless, mutations within pbmrp may also contribute to the CQ drug resistance phenotype.

The pbmrp locus was mapped to chromosome 13/14 in the drug sensitive $\mathrm{N}$ clone. Similarly, synteny analysis between the $P$. falciparum and the $P$. $y$. yoelii genome indicate that pymrp is located in chromosome 14 [73]. How- 
ever, a striking finding in our study was that unlike $\mathrm{N}$ clone, the CQ selected line RC exhibited a chromosomal translocation of this gene to chromosome 8 (Figure 6). In a CQ resistant $P$. falciparum isolates subjected to mefloquine selection and constant drug pressure, pfmdr1, a member of the ABCB transporter sub-family, was amplified resulting in an increase in size of chromosome 5 [74]. A partial chromosomal duplication of the region containing the mdr1 gene was described in a Plasmodium chabaudi line selected for a stable mefloquine-resistance, where a second copy was translocated from chromosome 12 to chromosome 4 [75]. Pyrimethamine selection of a $P$. chabaudi line resulted in the duplication of the DHFR gene and a rearrangement of chromosome 7 [76]. The detection of pbmrp solely in chromosome 8 in the RC line and the fact that this chromosome appears to be of similar size as its counterpart in the drug sensitive $\mathrm{N}$ clone support that our observation is a translocation event without gene duplication. Previous work mapped the pbggcs gene to chromosome 8 in the P. berghei lines studied [54]. Cotransfection experiments in Leishmania with the genes for PGPA and GGCS demonstrated that they work synergistically to confer resistance to antimony [77].

Therefore, the relocation of the pbmrp gene to the same chromosome of a potential linked gene, pbggcs, is intriguing and deserves further examination. It remains to be established whether pbMRP transports anions such as GSH, and/or GSH S-conjugates and whether it confers resistance to any anti-malarials.

\section{Conclusion}

The $P$. berghei mrp gene was sequenced and compared to homologues of this gene in other Plasmodium species and organisms. Using bioinformatics the pbmrp gene was found to have the highly conserved $\mathrm{ABC}$ motifs and was classified as an ABCC/MRP2 type membrane transporter.

There were no differences in gene organization, copy number, or level of expression when comparing a drug sensitive and a CQ selected drug resistant $P$. berghei line. A chromosomal translocation of the pbmrp gene from chromosome 13/14 to chromosome 8 was observed when comparing the drug sensitive $\mathrm{N}$ clone and the CQ resistant line RC.

The fact that some of these proteins are involved in the drug resistance phenomenon in other species justifies further investigations on the potential contribution of $A B C$ transporters to anti-malarial resistance in Plasmodium. The results of this study justify the examination of the role of the Plasmodium berghei multidrug resistance associated protein in Plasmodium detoxification pathways. Future research on membrane transport mechanisms and intracellular biochemical processes mediated by these trans- porters could result in the identification of novel drug targets or multidrug treatment strategies to combat malaria.

\section{Competing interests}

The authors declare that they have no competing interests.

\section{Authors' contributions}

MGP participated in the work for the biological assays, performed the bioinformatic analyses, and drafted the manuscript and figures. ACS contributed to the study design, participated in the work for the biological assays, performed the sequencing experiments, carried out some bioinformatic analyses, and helped draft the manuscript. ACS submitted part of this work in partial fulfillment of her doctoral dissertation. RGM designed, supervised, and carried out part of the bioinformatics analyses. RGM carried out the phylogenetic analysis. RGM also helped draft the manuscript and figures. AES contributed to the design of the study, was responsible for the supervision of the work, and helped draft the manuscript. All authors read and approved the final manuscript

\section{Additional material}

\section{Additional file 1}

Primers used in pbmrp sequencing reactions. Table that includes all the primer combinations used to sequence the pbmrp gene in the Plasmodium berghei $N$ clone line. Forward and reverse primers are prefaced with an $F$ or an $R$, respectively.

Click here for file

[http://www.biomedcentral.com/content/supplementary/14752875-8-1-S1.pdf]

\section{Additional file 2}

Complete pbmrp nucleotide sequence and predicted amino acid sequence. The complete nucleotide sequence of the pbmrp gene from the Plasmodium berghei line is presented together with the predicted protein sequence.

Click here for file

[http://www.biomedcentral.com/content/supplementary/1475-

2875-8-1-S2.pdf]

\section{Additional file 3}

Complete multiple sequence alignment the MRP sequences from five Plasmodium species. The complete multiple sequence alignment for the MRPs obtained from five Plasmodium species: P. y. yoelii, P. berghei, $\mathrm{P}$. vivax, P. knowlesi, and P. falciparum, is show.

Click here for file

[http://www.biomedcentral.com/content/supplementary/14752875-8-1-S3.pdf]

\section{Acknowledgements}

This project was supported by NIGMS/MBRS award GM08224 and received partial support from the RCMI award GI2RR0305 I of the NCRR/ $\mathrm{NIH}$. MGP acknowledges the partial support received through the MBRS/ 
RISE award R25GM06/838. In addition, RGM acknowledges funding through NIH NIGMS grant No. 2 T36GM008789-04AI and acknowledges the use of the Pittsburgh Supercomputing Center National Resource for Biomedical Supercomputing resources funded through NIH NCRR grant 2 P4I RR06009-I6AI. The authors also thank Wallace Peters and Brian Robinson for the $P$. berghei lines and advice. A special thanks to Hugh Nicholas for his helpful discussions and critical reading of the manuscript.

\section{References}

I. Wilson CM, Serrano AE, Wasley A, Bogenschutz MP, Shankar AH, Wirth DF: Amplification of a gene related to mammalian $\mathbf{m d r}$ genes in drug-resistant Plasmodium falciparum. Science 1989, 244: II84-II86.

2. Reed MB, Saliba KJ, Caruana SR, Kirk K, Cowman AF: Pgh I modulates sensitivity and resistance to multiple antimalarials in Plasmodium falciparum. Nature 2000, 403:906-909.

3. Fidock DA, Nomura T, Talley AK, Cooper RA, Dzekunov SM, Ferdig MT, Ursos LM, Sidhu AB, Naude B, Deitsch KW, Su XZ, Wootton JC, Roepe PD, Wellems TE: Mutations in the $P$. falciparum digestive vacuole transmembrane protein PfCRT and evidence for their role in chloroquine resistance. Mol Cell 2000, 6:86I-87I.

4. Sidhu AB, Uhlemann AC, Valderramos SG, Valderramos JC, Krishna $S$, Fidock DA: Decreasing pfmdrl copy number in Plasmodium falciparum malaria heightens susceptibility to mefloquine, lumefantrine, halofantrine, quinine, and artemisinin. J Infect Dis 2006, 194:528-535.

5. Mu J, Ferdig MT, Feng $X$, Joy DA, Duan J, Furuya T, Subramanian G, Aravind L, Cooper RA, Wootton JC, Xiong M, Su XZ: Multiple transporters associated with malaria parasite responses to chloroquine and quinine. Mol Microbiol 2003, 49:977-989.

6. Anderson TJ, Nair S, Qin H, Singlam S, Brockman A, Paiphun L, Nosten F: Are transporter genes other than the chloroquine resistance locus ( $p f c r t$ ) and multidrug resistance gene (pfmdr) associated with antimalarial drug resistance. Antimicrob Agents Chemother 2005, 49:2180-2I88.

7. Szeto AC, Pérez-Rosado J, Ferrer-Rodríguez I, Vega J, Torruella-Thillet $C$, Serrano $A E$ : Identification and expression analysis of ABC genes in Plasmodium yoelii and $P$. berghei. Parasitol Res 2004, 92: I-II.

8. Valderramos SG, Fidock DA: Transporters involved in resistance to antimalarial drugs. Trends Pharmacol Sci 2006, 27:594-601.

9. Walker JE, Eberle A, Gay NJ, Runswick MJ, Saraste M: Conservation of structure in proton-translocating ATPases of Escherichia coli and mitochondria. Biochem Soc Trans 1982, 10:203-206.

10. Diederichs K, Diez J, Greller G, Muller C, Breed J, Schnell J, Vonrhein C, Boos W, Welte W: Crystal structure of MalK, the ATPase subunit of the trehalose/maltose ABC transporter of the archaeon Thermococcus litoralis. Embo J 2000, 19:595I-596I.

II. Hyde SC, Emsley P, Hartshorn MJ, Mimmack MM, Gileadi U, Pearce SR, Gallagher MP, Gill DR, Hubbard RE, Higgins CF: Structural model of ATP-binding proteins associated with cystic fibrosis, multidrug resistance and bacterial transport. Nature 1990 , 346:362-336.

12. Linton KJ, Higgins CF: The Escherichia coli ATP-binding cassette (ABC) proteins. Mol Microbiol I998, 28:5-13.

13. Linton KJ: Structure and function of ABC transporters. Physiology 2007, 22:122-130.

14. Loe DW, Deeley RG, Cole SP: Characterization of vincristine transport by the $M(r) \quad 190,000$ multidrug resistance protein (MRP): evidence for cotransport with reduced glutathione. Cancer Res 1998, 58:5130-136.

15. Deeley RG, Westlake C, Cole SP: Transmembrane transport of endo- and xenobiotics by mammalian ATP-binding cassette multidrug resistance proteins. Physiol Rev 2006, 86:849-899.

16. Dean M, Allikmets R: Complete characterization of the human ABC gene family. I Bioenerg Biomembr 200I, 33:475-479.

17. Kruh GD, Belinsky MG: The MRP family of drug efflux pumps. Oncogene 2003, 22:7537-7552.

18. Deeley RG, Cole SP: Substrate recognition and transport by multidrug resistance protein I (ABCCI). FEBS Lett 2006, 580:1103-1111.

19. Broeks A, Gerrard B, Allikmets R, Dean M, Plasterk RH: Homologues of the human multidrug resistance genes MRP and
MDR contribute to heavy metal resistance in the soil nematode Caenorhabditis elegans. EMBO J 1996, 15:6|32-6|43.

20. Lu YP, Li ZS, Rea PA: AtMRPI gene of Arabidopsis encodes a glutathione S-conjugate pump: isolation and functional definition of a plant ATP-binding cassette transporter gene. Proc Natl Acad Sci USA 1997, 94:8243-8248.

2I. Lu YP, Li ZS, Drozdowicz YM, Hortensteiner S, Martinoia E, Rea PA: AtMRP2, an Arabidopsis ATP binding cassette transporter able to transport glutathione S-conjugates and chlorophyll catabolites: functional comparisons with AtmrpI. Plant Cell 1998, 10:267-82.

22. Tommasini R, Vogt E, Fromenteau M, Hörtensteiner S, Matile P, Amrhein N, Martinoia E: An ABC-transporter of Arabidopsis thaliana has both glutathione-conjugate and chlorophyll catabolite transport activity. Plant J I998, 1 3:773-780.

23. Li ZS, Szczypka M, Lu YP, Thiele DJ, Rea PA: The yeast cadmium factor protein (YCFI) is a vacuolar glutathione S-conjugate pump. J Biol Chem 1996, 27 I:6509-65I 7.

24. Shahi SK, Krauth-Siegel RL, Clayton CE: Overexpression of the putative thiol conjugate transporter TbMRPA causes melarsoprol resistance in Trypanosoma brucei. Mol Microbiol 2002, 43: I I29-II 38.

25. Coelho AC, Beverley SM, Cotrim PC: Functional genetic identification of PRPI, an ABC transporter superfamily member conferring pentamidine resistance in Leishmania major. Mol Biochem Parasitol 2003, I 30:83-90.

26. El Fadili K, Messier N, Leprohon P, Roy G, Guimond C, Trudel N, Saravia NG, Papadopoulou B, Legare D, Ouellette M: Role of the ABC transporter MRPA (PGPA) in antimony resistance in Leishmania infantum axenic and intracellular amastigotes. Antimicrob Agents Chemother 2005, 49:1 1988-1993.

27. Coelho AC, Messier N, Ouellette M, Cotrim PC: Role of the ABC transporter PRPI (ABCC7) in pentamidine resistance in Leishmania amastigotes. Antimicrob Agents Chemother 2007, 5 I:3030-3032.

28. Légaré D, Papadopoulou B, Roy G, Mukhopadhyay R, Haimeur A, Dey S, Grondin K, Brochu C, Rosen BP, Ouellette M: Efflux systems and increased trypanothione levels in arsenite-resistant Leishmania. Exp Parasito 1997, 87:275-282.

29. Papadopoulou B, Roy G, Dey S, Rosen BP, Ouellette M: Contribution of the Leishmania P-glycoprotein-related gene ItpgpA to oxyanion resistance. J Biol Chem 1994, 269: I 1980-I I 986.

30. Klokouzas A, Tiffert T, van Schalkwyk D, Wu CP, van Veen HW, Barrand MA, Hladky SB: Plasmodium falciparum expresses a multidrug resistance-associated protein. Biochem Biophys Res Commun 2004, 321 : 197-201.

31. Le Roch KG, Zhou Y, Blair PL, Grainger M, Moch JK, Haynes JD, De La Vega P, Holder AA, Batalov S, Carucci DJ, Winzeler EA: Discovery of gene function by expression profiling of the malaria parasite life cycle. Science 2003, 30 I: I503-1508.

32. Ursing J, Zakeri S, Gil JP, Björkman A: Quinoline resistance associated polymorphisms in the pfort, pfmdrl and pfmrp genes of Plasmodium falciparum in Iran. Acta Trop 2006, 97:352-356.

33. Peters W: Drug resistance in Plasmodium berghei Vincke and Lips, 1948. I. Chloroquine resistance. Exp Parasitol 17:80-89.

34. Peters W: Chemotherapy and Drug Resistance in Malaria Volume I. London: Academic Press; 1987.

35. Peters $W$ : The chemotherapy of rodent malaria, XXII. The value of drug-resistant strains of $P$. berghei in screening for blood schizontocidal activity. Ann Trop Med Parasitol 1975, 69:155-171.

36. Sanderson A, Walliker D, Molez J: Enzyme typing of Plasmodium falciparum from African and some other Old World countries. Trans R Soc Trop Med Hyg 198I, 75:263-267.

37. Barker RH, Suebsaeng L, Rooney W, Alecrim GC, Dourado HV, Wirth DF: Specific DNA probes for the diagnosis of Plasmodium falciparum malaria. Science 1986, 23 I: | |434- 1436.

38. Serrano AE, Robinson BL, Peters W, Trujillo-Nevárez K: Plasmodium berghei and Plasmodium yoelii: molecular karyotypes of drug-resistant lines. Exp Parasitol 1999, 91:93-96.

39. Quevillon E, Silventoinen V, Pillai S, Harte N, Mulder N, Apweiler R, Lopez R: InterProScan: protein domains identifier. Nucleic Acids Res 2005, 33:WII6-120.

40. Marchler-Bauer A, Panchenko AR, Shoemaker BA, Thiessen PA, Geer LY, Bryant SH: CDD: a database of conserved domain align- 
ments with links to domain three-dimensional structure. Nucleic Acids Res 2002, 30:28I-283.

41. Krogh A, Larsson B, von Heijne G, Sonnhammer EL: Predicting transmembrane protein topology with a hidden Markov model: application to complete genomes. J Mol Biol 200I, 305:567-580.

42. Cserzo M, Wallin E, Simon I, von Heijne G, Elofsson A: Prediction of transmembrane alpha-helices in procariotic membrane proteins: the Dense Alignment Surface method. Prot Eng 1997, 10(6):673-676

43. Bahl A, Brunk B, Coppel RL, Crabtree J, Diskin SJ, Fraunholz MJ, Grant GR, Gupta D, Huestis RL, Kissinger JC, Labo P, Li L, McWeeney SK, Milgram AJ, Roos DS, Schug J, Stoeckert CJ Jr: PlasmoDB: the Plasmodium genome resource. An integrated database providing tools for accessing, analyzing and mapping expression and sequence data (both finished and unfinished). Nucleic Acids Res 2002, 30:87-90.

44. Altschul SF, Gish W, Miller W, Myers EW, Lipman DJ: Basic local alignment search tool. J Mol Biol 1990, 215:403-410.

45. Altschul SF, Madden TL, Schäffer AA, Zhang J, Zhang Z, Miller W, Lipman DJ: Gapped BLAST and PSI-BLAST: a new generation of protein database search programs. Nucleic Acids Res 1997, 25:3389-3402.

46. Higgins D, Thompson J, Gibson T, Thompson JD, Higgins DG, Gibson T]: CLUSTAL W: improving the sensitivity of progressive multiple sequence alignment through sequence weighting, position-specific gap penalties and weight matrix choice. Nucleic Acids Res 1994, 22:4673-4680.

47. Nicholas KB, Nicholas HB Jr, Deerfield DW II: GeneDoc: Analysis and Visualization of Genetic Variation. EMBNEW NEWS 1997, 4:14.

48. Castresana J: Selection of conserved blocks from multiple alignments for their use in phylogenetic analysis. Mol Biol Evol 2000, 17:540-552 [http://molevol.cmima.csic.es/castresana/ Gblocks server.html].

49. Felsenstein J: Evolutionary trees from DNA sequences: a maximum likelihood approach. J Mol Evol 198I, 17:368-376 [http:// evolution.genetics.washington.edu/phylip/software.html].

50. Saitou N, Nei M: The neighbor-joining method: a new method for reconstructing phylogenetic trees. Mol Biol Evol 1987, 4:406-425.

5I. Gervais G, Trujillo K, Robinson BL, Peters W, Serrano AE: Plasmodium berghei: identification of an $\mathbf{m d r}$ like gene associated with drug resistance. Exp Parasitol 1999, 91:86-92.

52. Ponzi M, Janse CJ, Dore E, Scotti R, Pace T, Reterink TJ, Berg FM van der, Mons B: Generation of chromosome size polymorphism during in vivo mitotic multiplication of Plasmodium berghei involves both loss and addition of subtelomeric repeat sequences. Mol Biochem Parasitol 1990, 41:73-82.

53. Birago C, Pace T, Picci L, Picci E, Scotti R, Ponzi M: The putative gene for the first enzyme of glutathione biosynthesis in Plasmodium berghei and Plasmodium falciparum. Mol Biochem Parasitol 1999, 99:33-40.

54. Pérez-Rosado J, Gervais GW, Ferrer-Rodríguez I, Peters W, Serrano AE: Plasmodium berghei: analysis of the gamma-glutamylcysteine synthetase gene in drug-resistant lines. Exp Parasitol 2002, 101:175-82

55. Hayakawa T, Culleton R, Otani H, Horii T, Tanabe K: Big bang in the evolution of extant malaria parasites. Mol Biol Evol 2008 25:2233-2239.

56. Nies $A T$, Keppler $D$ : apical conjugate efflux pump $A B C C 2$ (MRP2). Pflugers Arch 2007, 453:643-59.

57. Jedlitschky G, Keppler D: Transport of leukotriene C4 and structurally related conjugates. Vitam Horm 2002, 64: 153-184.

58. König J, Nies AT, Cui Y, Keppler D: MRP2, the apical export pump for anionic conjugates. In $A B C$ proteins: from bacteria to man Edited by: Holland IB, Kuchler K, Higgins C, Cole SPC. London: Academic; 2003:423-443.

59. Koike K, Kawabe T, Tanaka T, Toh S, Uchiumi T, Wada M, Akiyama $S$, Ono M, Kuwano M: A canalicular multispecific organic anion transporter (cMOAT) antisense cDNA enhances drug sensitivity in human hepatic cancer cells. Cancer Res 1997, 57:5475-5479.

60. Cui Y, König J, Buchholz U, Spring H, Leier I, Keppler D: Drug resistance and ATP-dependent conjugate transport mediated by the apical multidrug resistance protein, MRP2, permanently expressed in human and canine cells. Mol Pharmacol 1999, 55:929-937.

6I. König J, Nies AT, Cui Y, Leier I, Keppler D: Conjugate export pumps of the multidrug resistance protein (MRP) family: localization, substrate specificity, and MRP2-mediated drug resistance. Biochim Biophys Acta 1999, 1461:377-394.

62. Bakos E, Hegedüs T, Holló Z, Welker E, Tusnády GE, Zaman GJ, Flens MJ, Váradi A, Sarkadi B: Membrane topology and glycosylation of the human multidrug resistance-associated protein. J Biol Chem 1996, 27 I: I 2322-I2326.

63. Belinsky MG, Bain LJ, Balsara BB, Testa JR, Kruh GD: Characterization of MOAT-C and MOAT-D, new members of the MRP/ cMOAT subfamily of transporter proteins. J Natl Cancer Inst 1998, 90:1735-1741.

64. Hopper E, Belinsky MG, Zeng H, Tosolini A, Testa JR, Kruh GD Analysis of the structure and expression pattern of MRP7 (ABCCI0), a new member of the MRP subfamily. Cancer Lett 2001, 162: $181-191$.

65. Lee K, Belinsky MG, Bell DW, Testa JR, Kruh GD: Isolation of MOAT-B, a widely expressed multidrug resistance-associated protein/canalicular multispecific organic anion transporter-related transporter. Cancer Res 1998, 58:274I-2747.

66. Bera TK, Lee S, Salvatore G, Lee B, Pastan I: MRP8, a new member of ABC transporter superfamily, identified by EST database mining and gene prediction program, is highly expressed in breast cancer. Mol Med 200I, 7:509-5I6.

67. Bera TK, lavarone C, Kumar V, Lee S, Lee B, Pastan I: MRP9, an unusual truncated member of the ABC transporter superfamily, is highly expressed in breast cancer. Proc Natl Acad Sci USA 2002, 99:6997-7002.

68. Higgins CF, Linton KJ: The ATP switch model for ABC transporters. Nat Struct Mol Biol 2004, I I:9 8-926.

69. Taniguchi K, Wada M, Kohno K, Nakamura T, Kawabe T, Kawakami M, Kagotani K, Okumura K, Akiyama S, Kuwano M: A human canalicular multispecific organic anion transporter (cMOAT) gene is overexpressed in cisplatin-resistant human cancer cell lines with decreased drug accumulation. Cancer Res 1996 , 56:4I24-4I29.

70. Ashutosh, Sundar S, Goyal N: Molecular mechanisms of antimony resistance in Leishmania. J Med Microbiol 2007, 56: I 43-I 53.

7I. Narang VS, Fraga C, Kumar N, Shen J, Throm S, Stewart CF, Waters $C M$ : Dexamethasone increases expression and activity of multi-drug resistance transporters at the rat blood-brain barrier. Am J Physiol Cell Physiol in press.

72. Lim AS, Cowman AF: Plasmodium falciparum: chloroquine selection of a cloned line and DNA rearrangements. Exp Parasitol 1996, 83:283-94.

73. Kooij TW, Carlton JM, Bidwell SL, Hall N, Ramesar J, Janse C], Waters AP: A Plasmodium whole-genome synteny map: indels and synteny breakpoints as foci for species-specific genes. PLoS Pathog 2005, I:e44.

74. Cowman AF, Galatis D, Thompson JK: Selection for mefloquine resistance in Plasmodium falciparum is linked to amplification of the pfmdrl gene and cross-resistance to halofantrine and quinine. Proc Natl Acad Sci USA 1994, 9 I: I I 43- I I 47.

75. Cravo PV, Carlton JM, Hunt P, Bisoni L, Padua RA, Walliker D Genetics of mefloquine resistance in the rodent malaria parasite Plasmodium chabaudi. Antimicrob Agents Chemother 2003, 47:709-7।8.

76. Cowman AF, Lew AM: Chromosomal rearrangements and point mutations in the DHFR-TS gene of Plasmodium chabaudi under antifolate selection. Mol Biochem Parasitol 1990 42:2I-29.

77. Grondin K, Haimeur A, Mukhopadhyay R, Rosen BP, Ouellette M Co-amplification of the gamma-glutamylcysteine synthetase gene gsh I and of the ABC transporter gene pgpA in arseniteresistant Leishmania tarentolae. EMBO J 1997, 16:3057-3065. 